\title{
Cold Plasma Source of Upflowing Ionospheric Ions in the Nightside Auroral Ionosphere
}

\author{
A. W. $\mathrm{YAU}^{1,2}$, T. $\mathrm{ABE}^{3}$, and B. A. WhaLeN ${ }^{2}$ \\ ${ }^{1}$ Department of Physics and Astronomy, University of Calgary, Calgary, Alberta, Canada T2N 1N4 \\ ${ }^{2}$ Herzberg Institute of Astrophysics, National Research Council, Ottawa, Ontario, Canada K1A OR6 \\ ${ }^{3}$ College of Science and Engineering, Aoyama Gakuin University, Tokyo 157, Japan
}

(Received November 8, 1995; Revised April 5, 1996; Accepted April 11, 1996)

The frequent occurrence of energetic $\mathrm{O}^{+}$upflowing ionospheric ions (UFI) at high altitude during auroral substorms raises the question of the cold plasma source and acceleration altitude for the $\mathrm{O}^{+}$ions, and their possible effects on the substorm-time plasma sheet. Ion composition observations on Akebono in the nightside auroral ionosphere reveal the significant presence of thermal-energy ( $\mathrm{a}$ few $\mathrm{eV}$ ) $\mathrm{O}^{+}$ions in the $6000-10,000 \mathrm{~km}$ altitude region both during and between auroral substorms. Their upward flux normalized to $2000 \mathrm{~km}$ altitude is about $2 \times 10^{8}$ $\mathrm{cm}^{-2} \mathrm{~s}^{-1}$. They are believed to be a significant source of cold plasma for the energetic UFI. During auroral substorms, Akebono occasionally observes molecular $\left(\mathrm{N}_{2}^{+}\right.$and $\left.\mathrm{NO}^{+}\right)$upflowing ions up to $\sim 60 \mathrm{eV}$, in or near regions of auroral electron precipitation up to $10,000 \mathrm{~km}$ altitude. This suggests the occurrence of a fast ion acceleration process in the $F$-region or topside ionosphere, where freshly created molecular $\mathrm{N}_{2}^{+}$and $\mathrm{NO}^{+}$ions are accelerated to several eV or greater within their dissociative recombination lifetime ( $\sim$ a few minutes). Ground photometric observations and simultaneous particle measurements on sounding rockets confirm the presence of transversely accelerated ions (TAI) up to $\sim 200 \mathrm{eV}$ in the topside ionosphere (near $600 \mathrm{~km}$ altitude) within tens of seconds of substorm expansion onset. Such hundred-eV TAI are frequently observed on Akebono in latitudinally confined regions of the nightside auroral ionosphere down to $\sim 2000 \mathrm{~km}$ altitude. They can reach the so-called "parallel accceleration region" at $\sim 1-2 R_{E}$ altitude within a few minutes, where they are often accelerated further to $\mathrm{keV}$ energy and can typically reach the plasma sheet during a substorm. Their flux is an order of magnitude smaller than the thermal ion flux. They are believed to be a minor source of plasma for the energetic UFI. In contrast, the lower-energy $(\leq 10-\mathrm{eV}) \mathrm{O}^{+}$TAI are typically too slow to reach the parallel acceleration region during the substorm, as they are decelerated by gravitation or trapped by it and traverse repeatedly along the magnetic field line. Hence they constitute a possible source of quiet-time thermal ions in the parallel acceleration region. Another possible source of thermal ions in the region is the polar wind $\mathrm{O}^{+}$ions convected anti-sunward along the auroral oval from the dawn and dusk sectors. The thermal $\mathrm{O}^{+}$ions in the parallel acceleration region at $\sim 1-2 R_{E}$ altitude of the nightside auroral ionosphere are believed to be the dominant source of cold plasma for energetic UFI at high altitude; they can reach the plasma sheet during a substorm, thereby modifying its composition significantly.

\section{Introduction}

The ion composition measurements of Shelley et al. (1972) were the first indication that ions of terrestrial origin might constitute a substantial component of the energetic ion population in the active-time magnetosphere. These measurements showed that precipitating $\mathrm{O}^{+}$flux in the 1-10 keV range sometimes exceeded the accompanying $\mathrm{H}^{+}$flux during magnetic storms. Since then, a number of studies have demonstrated the substantial and variable presence of $\mathrm{O}^{+}$fluxes in the active-time plasma sheet (Lennartsson and Sharp, 1982) and tail lobes (Sharp et al., 1981). 
The first direct observation of energetic (keV) auroral upflowing ionospheric ions (UFI) was provided by Shelley et al. (1976). On S3-3 below $8000 \mathrm{~km}$ altitude, Ghielmetti et al. (1978) found that energetic UFI occur in a zone closely associated with the statistical auroral oval, and that their occurrence frequency increases with altitude. Gorney et al. (1981) found that upflowing ion beams occur primarily above $5000 \mathrm{~km}$. This suggests that parallel ion acceleration occurs predominantly in the so-called "parallel acceleration" region between $\sim 1$ and $2 R_{E}$ altitude.

On DE-1, Yau et al. (1985) reported the frequent occurrence of $100-\mathrm{eV} \mathrm{O}^{+} \mathrm{UFI}$ in the nightside auroral ionosphere. Yau et al. (1985) found that the heavy-to-light ion flux ratio $\left(\mathrm{O}^{+} / \mathrm{H}^{+}\right)$in UFI increases with the level of solar and magnetic activity. During magnetically active times near solar maximum, the $\mathrm{O}^{+}$UFI flux normalized to $2000 \mathrm{~km}$ altitude was about $3 \times 10^{8} \mathrm{~cm}^{-2} \mathrm{~s}^{-1}$. Collin et al. (1987) found that the $\mathrm{O}^{+} / \mathrm{H}^{+}$energy ratio also changes with solar activity.

In the nightside auroral ionosphere, the frequent occurrence of $\mathrm{O}^{+}$-dominated energetic UFI (Yau et al., 1985) at high altitudes $(>8000 \mathrm{~km}$ ) raises the question of the cold plasma source for the $\mathrm{O}^{+}$UFI. On S3-3, Sharp et al. (1977) interpreted the observed ion conics as ions which were transversely accelerated at lower altitudes $(\sim 5000 \mathrm{~km})$ and then spiralled upward along the magnetic field as a consequence of adiabatic invariance. Assuming that the thermal-energy $\mathrm{O}^{+}$ions originated at the altitude of transverse acceleration, this interpretation would require an ambient $\mathrm{O}^{+}$density in the $\sim 5000-\mathrm{km}$ altitude region that is orders of magnitude larger than expected values based on typical topside ionospheric scale height considerations. Ion conics and TAI up to hundreds of eV were previously observed at lower altitudes: down to $2000 \mathrm{~km}$ on S3-3 (Gorney et al., 1981), at $1400 \mathrm{~km}$ on Isis-1 and -2 (Klumpar, 1979), and between 500 and 1000 $\mathrm{km}$ on sounding rockets (Whalen et al., 1978; Yau et al., 1983). However, mass composition information was not available from these measurements. Thus, the source of cold $\mathrm{O}^{+}$plasma for the energetic UFI at high altitude remains an open question.

Abe et al. (1993) recently studied the characteristics of the thermal plasma in the polar ionosphere between 2000 and $10000 \mathrm{~km}$ altitude, using the thermal ion composition measurements from the Akebono suprathermal mass spectrometer (SMS). Their study was concentrated in the latitude region above $80^{\circ}$, and represented the first comprehensive statistical study of the polar wind above $4000 \mathrm{~km}$ altitude. Abe et al. (1993) found that in the high-altitude polar cap poleward of the auroral oval, low energy (a few $\mathrm{eV}$ ) upflowing ions were regularly observed and were typically characteristic of the polar wind, in that they were field-aligned, and had temperature below 1 $\mathrm{eV}$, and parallel ion velocities which varied inversely with the ion mass. In the present study, we concentrate our analysis of the Akebono SMS data on the thermal ion flow in the parallel acceleration altitude region in the nightside auroral ionosphere.

Detailed description of the SMS instrument and its operations was presented elsewhere (Whalen et al., 1990). In this study, we present data acquired by SMS in its fast and mass scan modes. In its fast scan mode, SMS was programmed to sample thermal and suprathermal ions every other spin $(8 \mathrm{~s})$. In the thermal measurements, its retarding potential analyzer (RPA) rapidly stepped through 8 voltage steps in the -0.1 to $16.3 \mathrm{~V}$ range relative to the spacecraft ground every $64 \mathrm{~ms}$, and it sampled 4 mass steps every $256 \mathrm{~ms}$, typically $\mathrm{H}^{+}, \mathrm{He}^{+}, \mathrm{O}^{++}$and $\mathrm{O}^{+}$. In the suprathermal ion measurements, typically 4 or 8 energy-per-charge steps in the range of $0.1-4 \mathrm{keV}$ are sampled. In the mass scan mode, a 64-point ion mass per charge spectrum in the 0.9-64 AMU/q range was obtained every $1 \mathrm{~s}$ at a fixed RPA or suprathermal ion energy per charge setting, resulting in an 8-point angular spectrum for each of the 64 sampled mass steps per spin.

\section{Observations}

Data from SMS in the period of February to September 1990 and that of March to November 1991 were used in the present analysis. Data in the thermal fast scan mode were used to determine 


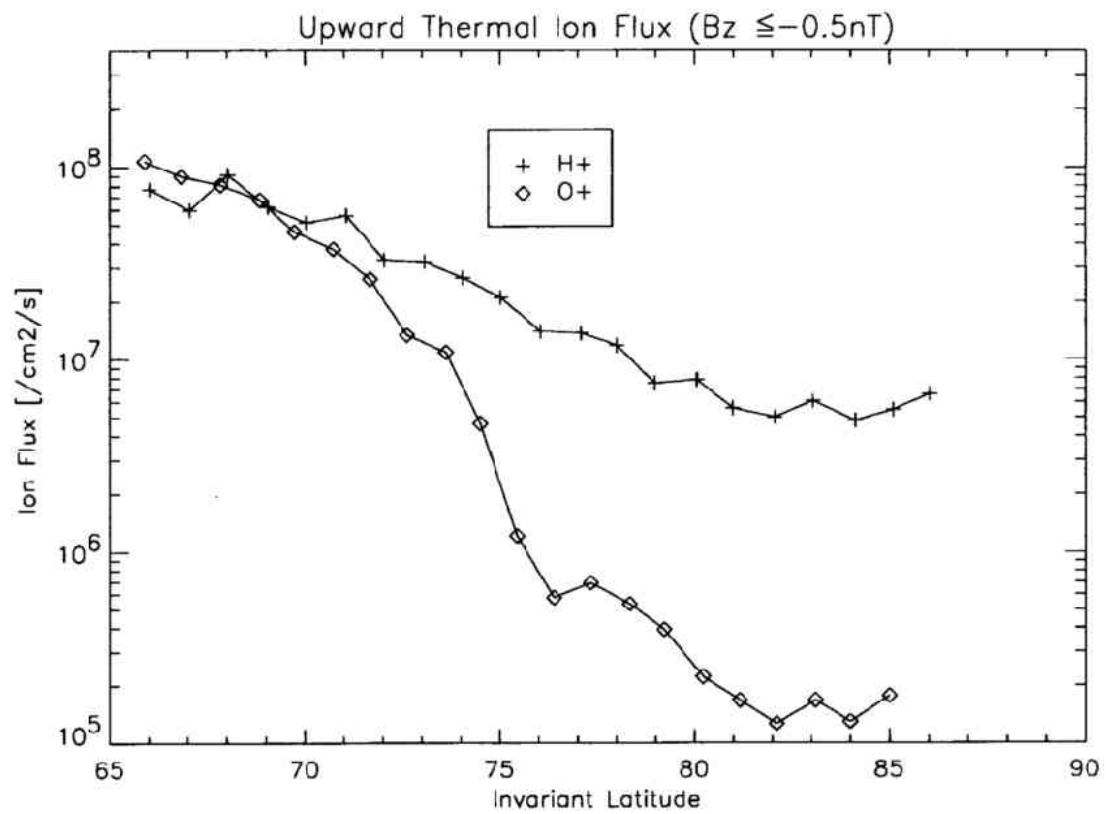

Fig. 1. Averaged $\mathrm{H}^{+}$(crosses) and $\mathrm{O}^{+}$(diamonds) thermal ion flux, observed at 6000-9000 km on Akebono in the midnight sector (21-03 MLT) sector and normalized to $2000 \mathrm{~km}$ altitude under southward IMF conditions $\left(B_{z} \leq-0.5 \mathrm{nT}\right)$ as a function of invariant latitude.

the spin-plane component of the parallel ion velocity $v_{\|}$and the ion density $n_{i}$, following the procedure presented in Watanabe et al. (1992) and Abe et al. (1993). Since the local magnetic field is nearly parallel to the spacecraft spin plane, $v_{\|}$is a good estimate of the parallel ion velocity. The ion density, $n_{i}$, was not been corrected for perpendicular (convection) drift and the spacecraft potential, and is believed to be lower limit estimates.

Figure 1 shows the averaged upward ion flux of thermal $\mathrm{H}^{+}$and $\mathrm{O}^{+}$ions at $6000-9000 \mathrm{~km}$ altitude in the midnight sector (21-03 MLT), at times of southward interplanetary magnetic field (IMF) as a function of invariant latitude. The flux was derived as the product of the averaged upward ion velocity and ion density, and was normalized to a reference altitude of $2000 \mathrm{~km}$ (by the ratio of magnetic field at the reference and measurement altitudes, respectively) in order to facilitate comparison with flux measurements at other altitudes. For both $\mathrm{H}^{+}$and $\mathrm{O}^{+}$, the largest flux was about $10^{8} \mathrm{~cm}^{-2} \mathrm{~s}^{-1}$, and was observed near $66^{\circ}$, the lowest invariant latitude at which data were available. The flux is believed to be a lower estimate since the ion density was likely to be an underestimate. In comparison, the observed fluxes in the other magnetic local time sectors (not shown) were peaked at higher invariant latitudes (typically above $75^{\circ}$ ). In selected orbit passes, the angular distribution of the observed ion flux was fitted to that of a drifting Maxwellian to obtain an estimate for the ion temperature. For both ion species, the ion temperature in all local time sectors was found to be typically $0.2-0.3 \mathrm{eV}$. Thus, the observed $\mathrm{H}^{+}$and $\mathrm{O}^{+}$ions in Fig. 1 are believed to be the cold (thermal-energy) plasma population in the parallel acceleration region of the nightside auroral ionosphere.

Figure 2 shows the variations of the upward ion flux with the magnetic $K p$ index. As in the previous figure, the flux was normalized to $2000 \mathrm{~km}$ altitude. The fluxes in the dusk, midnight, and dawn sectors are shown in dotted, solid, and dashed curves, respectively. For both ion species, the data were averaged over the $6000-9000 \mathrm{~km}$ altitude and $60^{\circ}-75^{\circ}$ invariant latitude 


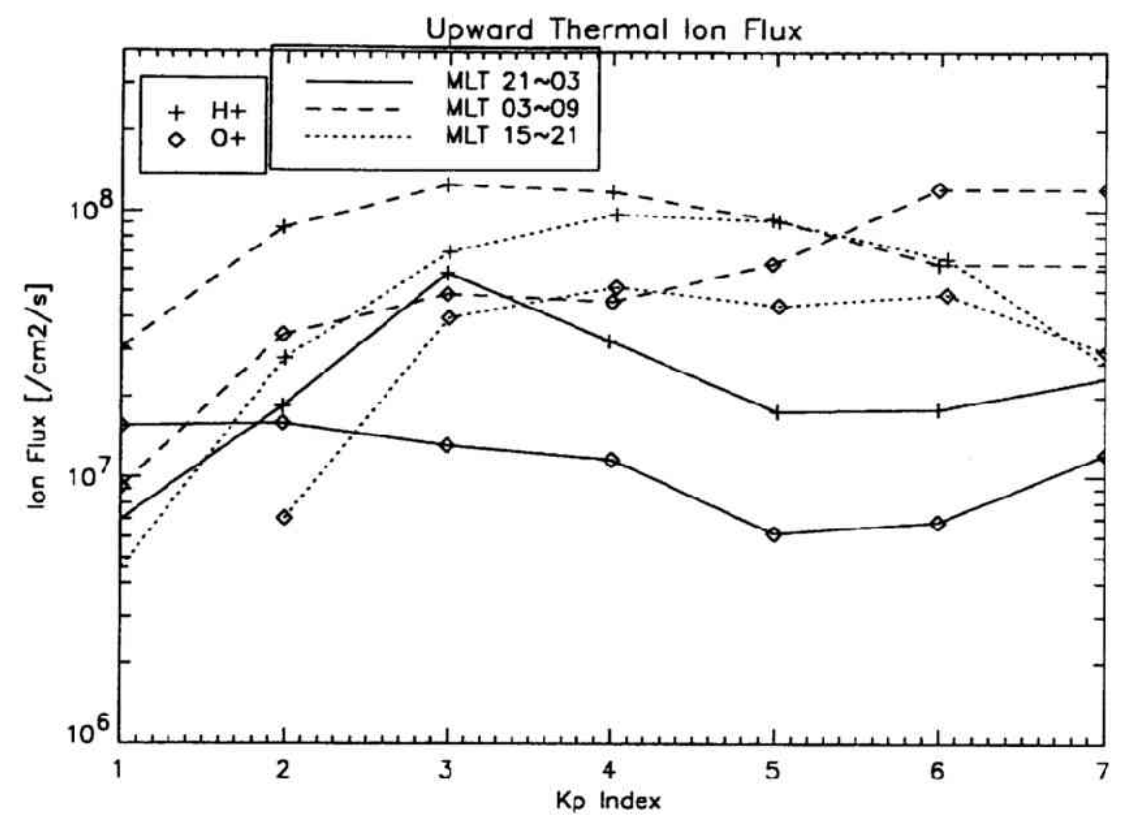

Fig. 2. Averaged $\mathrm{H}^{+}$(crosses) and $\mathrm{O}^{+}$(diamonds) thermal ion flux, observed at $6000-9000 \mathrm{~km}$ and $60^{\circ}-75^{\circ}$ invariant on Akebono in the midnight (21-03 MLT; solid curves), dawn (03-09 MLT; dashed curves), and dusk (15-21 MLT; dotted curves) sectors, and normalized to $2000 \mathrm{~km}$ altitude, as a function of $K p$ index.

region. The $\mathrm{O}^{+}$flux generally increases by a factor of $3-5$ as $K p$ increases from 2 to 6 in both the dawn and dusk sectors, but does not appear to vary much with $K p$ in the midnight sector. In comparison, the $\mathrm{H}^{+}$flux exhibits a more modest increase with $K p$ at quiet and moderately active times ( $K p$ below 4$)$, and decreases with increasing $K p$ at active times $(K p$ above 4$)$ in all three MLT sectors. Overall, the $\mathrm{O}^{+}$flux is comparable to the $\mathrm{H}^{+}$flux at active times, but is generally smaller than the $\mathrm{H}^{+}$flux at quiet times. To the extent that the $K p$ index represents an approximate measure of auroral activity (substorm) level, Fig. 2 suggests a moderate (factor of $2-3$ ) increase in the cold plasma $\mathrm{O}^{+} / \mathrm{H}^{+}$ratio in the auroral acceleration region during auroral substorms.

During periods of sustained auroral activities, the SMS occasionally observed significant fluxes of molecular upflowing ions in the auroral ionsophere (Yau et al., 1993). Figure 3 shows an ion mass spectrum observed in a molecular upflowing ion event on January 22, 1990 in an apogee pass ( $8700-9500 \mathrm{~km}$ altitude). The $K p$ index was $3^{+}$at this time, and had been above this level for most of the preceding 24 hours. Akebono was traversing the northern auroral zone near local midnight (23.1-23.7 MLT). Intense precipitating electron fluxes in the 1-10 keV range were observed between $73^{\circ}$ and $74^{\circ}$ invariant, andbetween $69^{\circ}$ and $70^{\circ}$ invariant. Molecular ions, composed predominantly of $\mathrm{N}_{2}^{+}$, were encountered immediately equatorward of the two regions of energetic electron precipitation.

Figure 3 shows the measured ion mass spectrum at 2134:33 UT, when molecular ions were encountered. It shows the ion count rate in the upward field line direction. The mass peaks at $1,4,8,16$, and $28 \mathrm{amu} / \mathrm{q}$ indicate the presence of $\mathrm{H}^{+}, \mathrm{He}^{+}, \mathrm{O}^{++}, \mathrm{O}^{+}$, and $\mathrm{N}_{2}^{+}$, respectively. The spectral width of the $\mathrm{N}_{2}^{+}$peak was $\sim 0.12$ (FWHM) and was significantly broader than that of the $\mathrm{He}^{+}$and $\mathrm{O}^{+}$peaks $(\mathrm{FWHM} \sim 0.07$ ), reflecting the presence of a smaller but nevertheless non-negligible component of the $\mathrm{NO}^{+}$ions in addition to $\mathrm{N}_{2}^{+}$ions. The difference between the 


\section{Jan 22, 1990 EXOS-D}
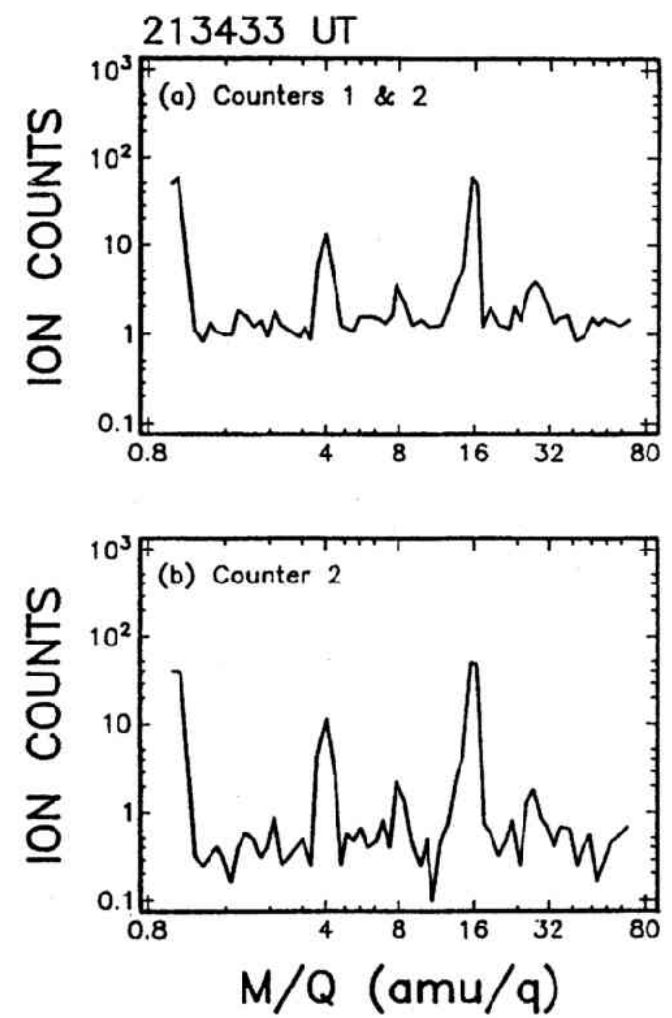

Fig. 3. Count rate of measured ions in the upward field line direction as a function of ion mass per charge, in molecular upflowing ion event on January 22, 1990 at 2134:33 UT. (a) 0-60 eV ions; (b) 5-60 eV ions. The $\mathrm{H}^{+}, \mathrm{He}^{+}$, and $\mathrm{O}^{+}$rates in (a) and (b) are essentially identical, indicating these ions were predominantly below $5 \mathrm{eV}$ in the spacecraft frame. The $\mathrm{N}_{2}^{+}$rate in (a) is about twice that in (b), indicating that the observed $\mathrm{N}_{2}^{+}$ions were predominantly above $5 \mathrm{eV}$.

upper and lower panels in Fig. 3 provides an estimate of ions above $5 \mathrm{eV}$ in the spacecraft frame. This is because the lower panel includes only data from detector counter " 2 " which is sensitive to all ions below $60 \mathrm{eV}$, whereas the upper panel includes in addition data from detector counter "1" which is insensitive to ions below $5 \mathrm{eV}$. The fact that the $\mathrm{H}^{+}, \mathrm{He}^{+}$, and $\mathrm{O}^{+}$count rates in the two panels are essentially identical indicates that these ions were predominantly below $5 \mathrm{eV}$ in the spacecraft frame. The fact that the $\mathrm{N}_{2}^{+}$count rate in the upper panel is about twice that in the lower panel indicates that a substantial fraction of the observed $\mathrm{N}_{2}^{+}$ions were in the 5-60 $\mathrm{eV}$ range.

The presence of significant molecular ion flux at high altitude (above $8000 \mathrm{~km}$ in this case) is indicative of their energization in the $F$-region or topside ionosphere. At auroral latitudes, molecular ions are created by electron impact ionization. In order to escape from the ionosphere in detectable quantities, they must acquire their escape energy in a time short compared with the local dissociative recombination lifetime, which is of the order of 5 minutes in the $F$-region and topside ionosphere (Yau et al., 1993). It is important to note that the potential energy of a 
molecular $\mathrm{N}_{2}^{+}$or $\mathrm{NO}^{+}$ion $(28$ or $30 \mathrm{AMU} / \mathrm{q})$ at $1 R_{E}$ altitude is about $10 \mathrm{eV}$. Therefore, the observed molecular ions in Fig. 3 must have been energized to above $15 \mathrm{eV}$ within a few minutes. In other words, the observation points to a fast ion energization process in the $F$-region or the topside ionosphere during active aurora. This is consistent with the evidence of fast ionospheric ion feeding to the inner magnetotail (Daglis and Axford, 1995).

In the nightside auroral ionosphere down to $2000 \mathrm{~km}$, Akebono frequently encounters regions of transverse ion acceleration, in which the observed ions are accelerated at $90^{\circ}$ pitch angles to $\sim 100-200 \mathrm{eV}$ (Whalen et al., 1991). The region of acceleration is latitudinally confined, and is often less than $100 \mathrm{~km}$. Transversely accelerated ions (TAI) have previously been observed below $1000 \mathrm{~km}$ altitude during auroral substorms (Whalen et al., 1978; Yau et al., 1983). Figure 4 shows the morphology of a large, multiple, pre-midnight auroral substorm at Churchill, Canada, on February 15, 1985, in which hundred-eV TAI were observed near $600 \mathrm{~km}$ altitude. The substorm consisted of a series of three distinct brightening and poleward expansion phases over a period of about 40 minutes. The three lower panels show the ground magnetograms. The three activation phases (expansion and brightening) of the substorm are clearly visible in the negative excursions of the $X$-magnetogram near 0510, 0521, and 0537 UT. The upper panel shows the integrated optical auroral emission intensity at $5577 \AA$ along the line of sight from a meridian scanning photometer. The intensity is shown as a function of time and elevation angle: $0^{\circ}$ corresponds to the northeast horizon ( $52^{\circ}$ azimuth), $180^{\circ}$ the southwest horizon, and $90^{\circ}$ the zenith at Churchill.

The auroral form was visible on the southern horizon before the onset of the substorm, and started to brighten in the east at 0507:30, reaching a peak intensity of 50-75 kR. It expanded poleward shortly thereafter (at 0509:30), reaching the zenith at 0510:15, receding rapidly equatorward, forming a NW-SE oriented multiple arc system to the south. The $X$-magnetogram displayed a $150 \mathrm{nT}$ negative bay during this poleward expansion. Then, at 0519:00, the multiple arc system began to brighten, and expanded poleward at 0520:40. The $X$-magnetogram showed a 200-nT negative bay during this poleward expansion. The auroral form continued its poleward motion at 0529:00, and started to break up at 0530:30. In the ensuring 5 minutes, its intensity dropped to below $10 \mathrm{kR}$. Then, at 0536:50, the third poleward expansion and brightening occurred, reaching a peak intensity in excess of $200 \mathrm{kR}$. At this time, the $X$-magnetogram showed a $-200 \mathrm{n}$ T excursion, and the $Z$-magnetogram showed a $500 \mathrm{nT}$ negative bay.

Figure 5 shows the measured ion and electron data from the MARIE sounding rocket, from 0535 to 0542 UT during the last of the three expansion phases and immediately preceding it. In and near the region of auroral electron precipitation during the substorm, transversely accelerated ions (TAI) up to $300 \mathrm{eV}$ were observed in the $500-600 \mathrm{~km}$ altitude region during the expansion phases. The instrument complement on the MARIE rocket and the detailed characteristics of the observed TAI were presented earlier (Kintner et al., 1986). Panel (a) and (b) show the precipitating ion flux at $47-366 \mathrm{eV}$ in the $0^{\circ}-90^{\circ}$ pitch angle range and the corresponding flux in the upgoing hemisphere $\left(90^{\circ}-120^{\circ}\right.$ pitch angles), respectively. Panel (c) and (d) show the more energetic components $(0.89-22.9 \mathrm{keV})$ of the ion fluxes. Panel (e) shows the precipitating auroral electron flux. The measured data were obtained from electrostatic analyzer ion and electron spectrometers which stepped through 16 energy steps and sampled a range of pitch angles as the rocket payload spinned and precessed. From the measured data, the pitch angle and energy distributions for both the ions and the electrons were subsequently reconstructed, and used to derive the integrated fluxes shown in the figure.

Auroral images from an image-intensified all-sky television camera at Churchill showed the onset of the poleward expansion at 0536:50. The aurora propagated eastward into the scanning photometer's field of view by $0537: 00$; $\mathrm{cf}$. Fig. 4 . Intense hundred-eV $\mathrm{H}^{+}$TAI were first observed near 0537:14, within seconds of the onset of the expansion. In the ensuring 30 seconds, the observed data were characterized by a distinct absence of energetic precipitating electrons (in 


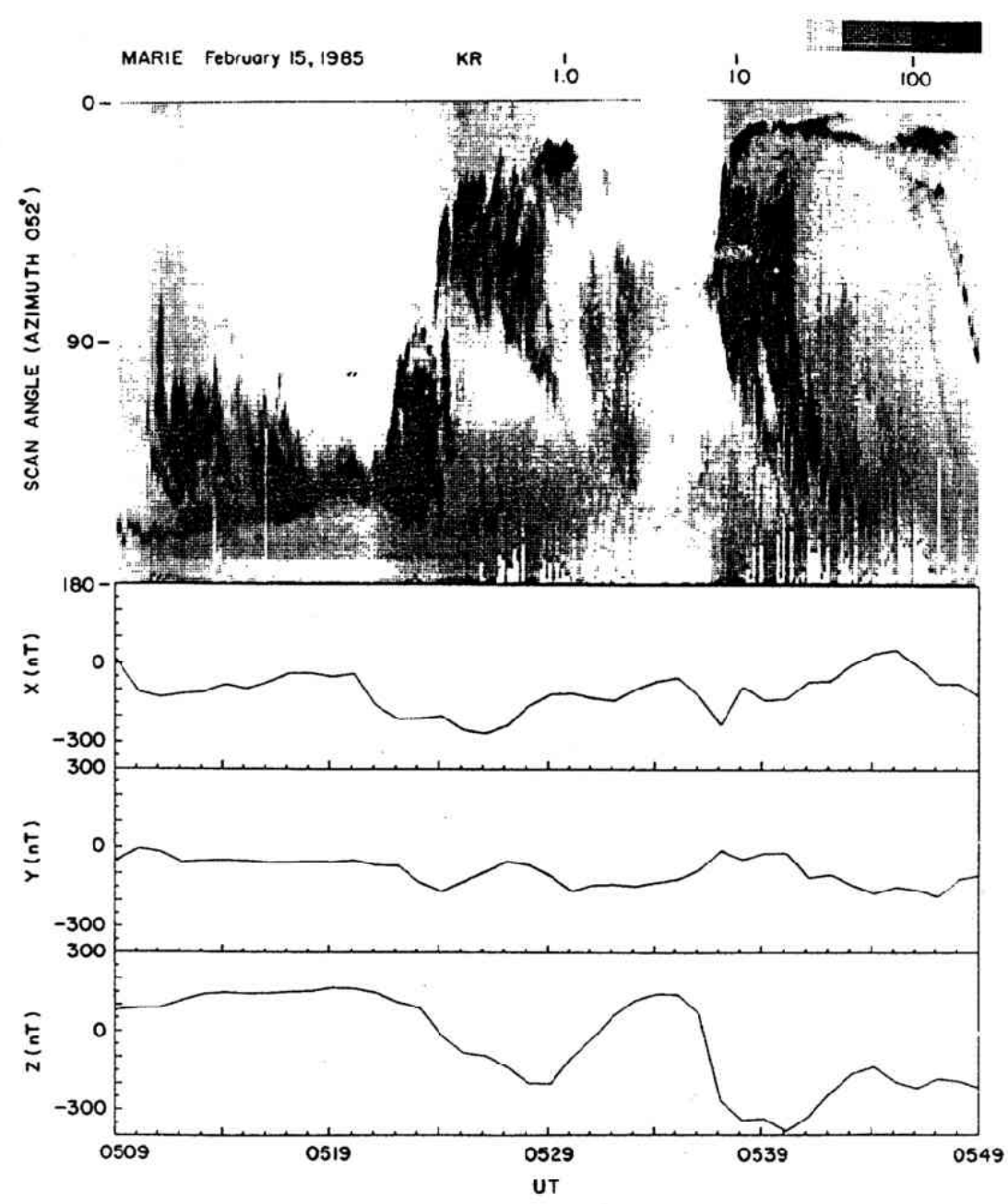

Fig. 4. Top panel: Integrated auroral intensity at $5577 \AA$ observed by ground meridian scanning photometer at Churchill, Canada, on February 15, 1985, during an auroral substorm with multiple expansions in which hundred-eV transversely accelerated ions (TAI) were observed near $600 \mathrm{~km}$ altitude. A scan angle of $0^{\circ}, 90^{\circ}$, and $180^{\circ}$ corresponds to the NE ( $52^{\circ}$ azimuth) horizon, the zenith, and the SW (272 ${ }^{\circ}$ azimuth) horizon, respectively. Bottom panels: $X, Y$, and $Z$-components of the ground magnetogram.

panel e). Also, the hundred-eV ion flux (panel b) was more than two orders of magnitude larger than the corresponding precipitating flux (panel a). This indicates that the observed ions originated from the ionosphere, and were not a mirroring population. During this time, the rocket payload traversed a horizontal distance of $16 \mathrm{~km}$ in a nearly perpendicular direction to the auroral form. The electron data therefore indicate that the observed TAI were as much as 10-15 $\mathrm{km}$ beyond the region of electron precipitation. Extremely intense ion fluxes were encountered from 0538:07 to 0538:12, when the ion spectrometers were saturated whenever they were stepping through the lowest energy steps (below $500 \mathrm{eV}$ ) and sampling the $90^{\circ}-120^{\circ}$ pitch angles. The saturation resulted in spurious counts (in panels $\mathrm{c}$ and d) in the higher energy measurements in the subsequent spectrometer stepping cycle. The intense TAI persisted until 0540:20, and their 


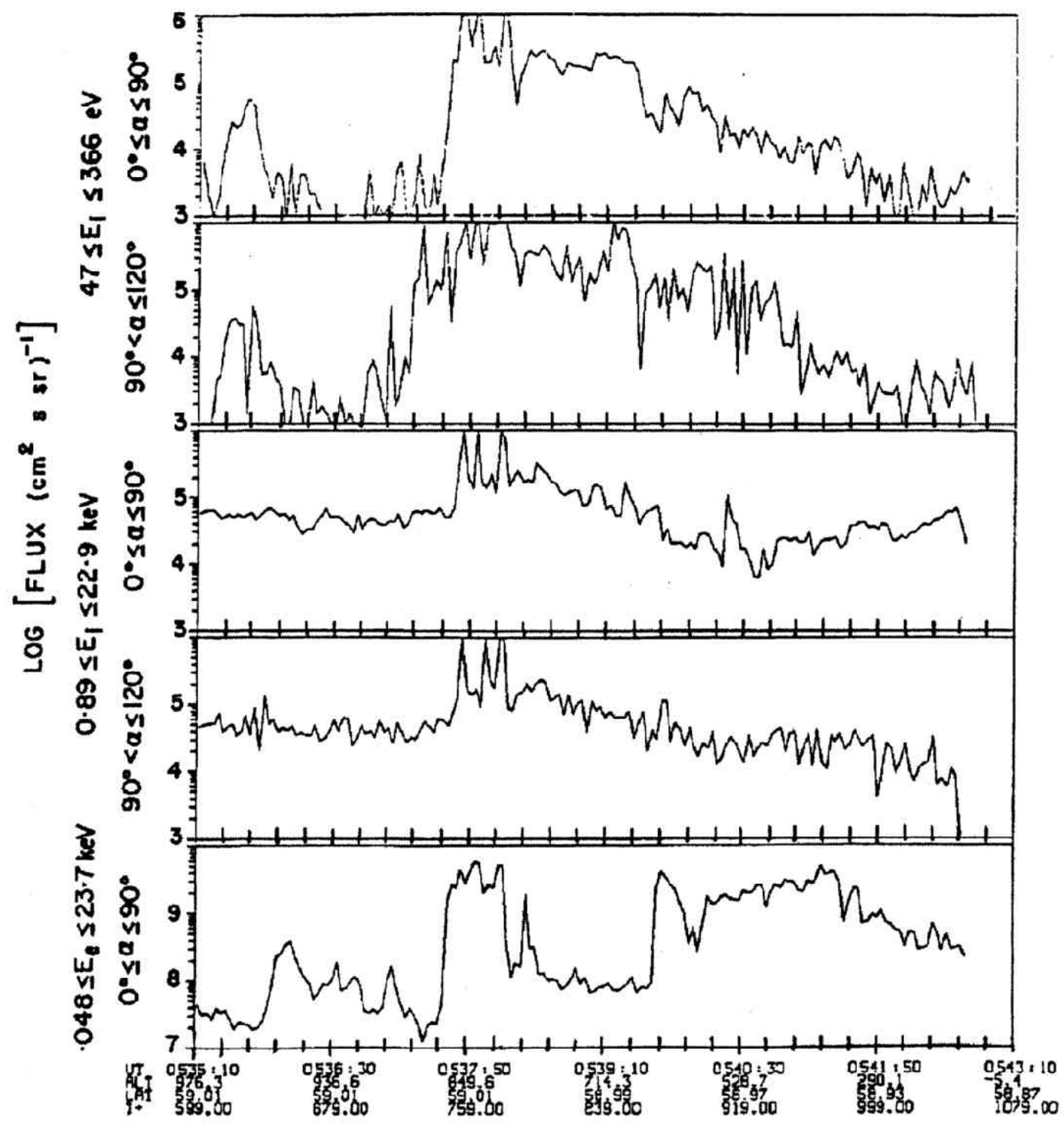

Fig. 5. Observed ion and electron fluxes from the MARIE rocket on February 15, 1985, during an auroral substorm with multiple expansions near midnight ( $\sim \mathrm{MLT}$ ). (a) $47-366 \mathrm{eV}$ ions $0^{\circ}-90^{\circ}$ pitch angles. (b) $47-366 \mathrm{eV}$ ions at $90^{\circ}-120^{\circ}$ pitch angles.(c) $0.89-22.9 \mathrm{keV}$ ions at $0^{\circ}-90^{\circ}$ pitch angles. (d) $0.89-22.9 \mathrm{keV}$ ions at $90^{\circ}-120^{\circ}$ pitch angles. (e) $0.048-23.7 \mathrm{keV}$ electrons at $0^{\circ}-90^{\circ}$ pitch angles.

flux was in the $10^{6}$ to $10^{7} \mathrm{~cm}^{-2} \mathrm{~s}^{-1}$ range.

Detailed pitch angle analysis showed that the TAI peaked near 105 at 0537:14 (895 km altitude), and near $90^{\circ}-95^{\circ}$ between 0539:40 and 0540:20 (651 to $555 \mathrm{~km}$ altitude). Assuming that the observed hundred-eV TAI at 0537:14 were injected at $600 \mathrm{~km}$ altitude (topside of the TAI source region) and then spiralled upward along the magnetic field, their transit time from 
the source to the observation altitude may be estimated. For $100-\mathrm{eV} \mathrm{H}^{+}$ions, the transit time would be $\sim 12.5 \mathrm{~s}$. Also, a peak pitch angle of $110^{\circ}$ would be expected at the observation altitude, compared with the observed value of $105^{\circ}$. Given the approximate nature of the analysis, the ions have been injected at $\sim 0537: 02$, within $\sim 15$ seconds after the onset of the optical auroral expansion and brightening at 0536:50. The data therefore confirm the occurrence of fast ion acceleration in the topside ionosphere at the onset of substorm expansion, as inferred from observations of molecular upflowing ions at high altitude (cf. Fig. 3).

\section{Summary and Discussion}

We have presented ion composition observations of thermal and suprathermal ions from the Akebono suprathermal mass spectrometer (SMS) in the nightside auroral ionosphere. These observations showed that:

1. In the parallel acceleration region near $1 R_{E}$ altitude, thermal $\mathrm{H}^{+}$and $\mathrm{O}^{+}$ions are frequently present. Their upward flux normalized to $2000 \mathrm{~km}$ altitude is about $10^{8} \mathrm{~cm}^{-2} \mathrm{~s}^{-1}$ (Fig. 1).

2. The $\mathrm{O}^{+} / \mathrm{H}^{+}$ratio of the upward thermal ion flux increases with the magnetic $K p$ index. The $\mathrm{O}^{+}$flux is smaller than the $\mathrm{H}^{+}$flux at quiet times, but is comparable to the latter at active times (Fig. 2).

3. The occasional presence of molecular upflowing ions in the $1-R_{E}$ altitude region indicates the occurrence of fast ion energization in the F-region or topside ionosphere during periods of sustained auroral activity (Fig. 3).

We have also presented ground photometric and simultaneous in-situ particle observations, which showed transverse ion acceleration to hundreds of $\mathrm{eV}$ near $600 \mathrm{~km}$ altitude in and near regions of auroral electron precipitation within $\sim 20$ seconds of the onset of auroral substorm expansions (Figs. 4 and 5). The flux of these hundred-eV TAI was on the order of $10^{6}-10^{7}$ $\mathrm{cm}^{-2} \mathrm{~s}^{-1}$. Whalen et al. (1991) observed the frequent occurrence of ions transversely accelerated to hundreds of $\mathrm{eV}$ in latitudinally confined regions of the nightside ionosphere down to $\sim 2000 \mathrm{~km}$ altitude during auroral substorms.

On DE-1 above $3.5 R_{E}$ altitude, Yau et al. (1985) found that energetic (hundred-eV and $\mathrm{keV}$ ) auroral upflowing $\mathrm{O}^{+}$ion flux increases significantly during active times. In the midnight sector (21-03 MLT), the peak flux is at $68^{\circ}$ invariant, and is about $3 \times 10^{8} \mathrm{~cm}^{-2} \mathrm{~s}^{-1}$ when normalized to $2000 \mathrm{~km}$ altitude. The upward thermal $\mathrm{O}^{+}$ion flux observed by Akebono in the "parallel acceleration region" near $1 R_{E}$ altitude is similar in magnitude and invariant latitude distribution. It represents a significant source of cold plasma for the energetic UFI at higher altitude.

The fact that the thermal $\mathrm{O}^{+}$ions are regularly present in the parallel acceleration region at quiet times suggests that they are available for energization at the onset of a substorm. Therefore, if they are accelerated to hundreds of $\mathrm{eV}$ or greater, they are capable of reaching the inner plasma sheet within the time scale of a substorm $(\sim 1 \mathrm{hr})$.

Hundred-eV $\mathrm{O}^{+} \mathrm{TAI}$ originating from the topside ionosphere at the onset of a substorm can reach the parallel acceleration region within a few minutes, and can likewise reach the plasma sheet during a substorm. However, their upward ion flux is an order of magnitude smaller than the thermal ion flux in the parallel acceleration region. Therefore, their contribution as a cold plasma source to the energetic UFI at high altitude is believed to be small in comparison.

Because of gravitation, lower-energy $(\leq 10-e V)$ TAI from the topside ionosphere are typically too slow to reach the parallel acceleration region during a substorm. Instead, they are likely to be trapped (or at least decelerated) between the topside ionosphere and some higher altitude. As they repeatedly traverse back and forth along the magnetic field line, they represent a source of thermal ions at high altitude, where they have near zero kinetic energy. A statistical study of 
these low-energy TAI at low altitude is needed to determine their possible importance as a source of thermal-energy plasma at higher altitude.

An alternative source of thermal ions in the parallel acceleration region is the polar wind $\mathrm{O}^{+}$ ions from the dawn and dusk sectors. Abe et al. (1993) found that $\mathrm{O}^{+}$ions constitute a significant component of the sunlit polar wind. On the dayside, the $\mathrm{O}^{+}$polar wind ion acquires a parallel ion velocity of $1-4 \mathrm{~km} / \mathrm{s}$ above $5000 \mathrm{~km}$. In comparison, the ion convection velocity at auroral latitudes is typically $\sim 1-2 \mathrm{~km} / \mathrm{s}$ at ionospheric altitudes, and is predominantly anti-sunward along the auroral oval (i.e., the tangential component of the convection velocity is large compared with the perpendicular component to the oval). Thus, the transit time of the polar wind $\mathrm{O}^{+}$ions from the dawn or dusk sector to the midnight sector is typically $\sim 1 \mathrm{hr}$, and the vertical distance traversed is about $0.5-1 R_{E}$. Thus, $\mathrm{O}^{+}$polar wind ions originating from the $5000-\mathrm{km}$ altitude region in the dawn and dusk sector can possibly convect to the parallel acceleration region in the nightside auroral ionosphere. A quantitative analysis of the three-dimensional velocity of the polar wind ions is needed to ascertain this possibility.

The regular presence of thermal $\mathrm{O}^{+}$ions in the parallel acceleration altitude region of the nightside auroral ionosphere strongly suggests that they are the dominant source of cold plasma for energetic UFI at high altitude, and that they can reach the plasma sheet during a substorm, thereby modifying its composition significantly. A number of authors have discussed the possible influence of the resultant plasma sheet mass loading on the dynamics of the substorm (Baker et al., 1982; Daglis and Axford, 1995). On the other hand, Lennartsson et al. (1993) argued against such influence on the basis of their ISEE-1 data. The effect of upflowing ionospheric ions on the dynamics of the substorm remains a controversial question.

We thank our many colleagues on the Akebono Science Team for their co-operations, the Canadian Space Agency for support of the Akebono Suprathermal Mass Spectrometer (SMS) Experiment, and the Natural Science and Engineering Research Council for its research grant.

\section{REFERENCES}

Abe, T., B. A. Whalen, A. W. Yau, R. E. Horita, S. Watanabe, and E. Sagawa, EXOS D (Akebono) Suprathermal Mass Spectrometer observations of the polar wind, J. Geophys. Res., 98, 11191-11203, 1993.

Baker, D. N., E. W. Hones, Jr., D. T. Young, and J. Birn, The possible role of ionospheric oxygen in the initiation and development of plasma sheet instabilities, Geophys. Res. Lett., 9, 1337-1340, 1982.

Collin, H. L., W. K. Peterson, and E. G. Shelley, Solar cycle variation of some mass dependent characteristics of upflowing beams of terrestrial ions, J. Geophys. Res., 92, 4757-6762, 1987.

Daglis, I. and W. I. Axford, Fast ionospheric response to enhanced activity in geospace: ion feeding of the inner magnetotail, J. Geophys. Res., 100, 1995 (in press).

Ghielmetti, A. G., R. G. Johnson, R. D. Sharp, and E. G. Shelley, The latitudinal, diurnal, and altitudinal distributions of upward flowing energetic ions of ionospheric origin, Geophys. Res. Lett., 5, 59-62, 1978.

Gorney, D. J., A. Clarke, D. Croley, J. F. Fennell, J. Luhmann, and P. F. Mizera, The distribution of ion beams and conics below $8000 \mathrm{~km}, J$. Geophys. Res., 86, 83-89, 1981.

Kintner, P. M., J. LaBelle, W. Scales, A. W. Yau, and B. A. Whalen, Observations of plasma waves within regions of perpendicular ion acceleration, J. Geophys. Res., 13, 1113-1116, 1986.

Klumpar, D. M., Transversely accelerated ions: an ionospheric source of hot magnetospheric ions, J. Geophys. Res., 84, 4229-4237, 1979.

Lennartsson, W., and R. D. Sharp, A comparison of the 0.1-17 keV/e ion composition in the near equatorial magnetosphere between quiet and disturbed conditions, J. Geophys. Res., 87, 6109-6120, 1982.

Lennartsson, W., D. M. Klumpar, E. G. Shelley, and J. M. Quinn, Experimental investigation of possible geomagnetic feedback from energetic $(0.1$ to $16 \mathrm{keV})$ terrestrial $\mathrm{O}^{+}$ions in the magnetotail current sheet, J. Geophys. Res., 98, 19443-19454, 1993.

Sharp, R. D., R. G. Johnson, and E. G. Shelley, Observation of an ionospheric acceleration mechanism producing energetic $(\mathrm{keV})$ ions primarily normal to the geomagnetic field direction, J. Geophys. Res., 82, 3324-3328, 1977. 
Sharp, R. D., D. L. Carr, W. K. Peterson, and E. G. Shelley, Ion streams in the magnetotail, J. Geophys. Res., 86, 4639-4648, 1981.

Shelley, E. G., R. G. Johnson, and R. D. Sharp, Satellite observations of energetic heavy ions during a magnetic storm, J. Geophys. Res., 77, 6104-6110, 1972.

Shelley, E. G., R. D. Sharp, and R. G. Johnson, Satellite observations of an ionospheric acceleration mechanism, Geophys. Res. Lett., 3, 654-656, 1976.

Watanabe, S., B. A. Whalen, and A. W. Yau, Thermal ion observations of depletion and refilling in the plasmaspheric trough, J. Geophys. Res., 97, 1081-1096, 1992.

Whalen, B. A., J. R. Burrows, A. W. Yau, E. E. Budzinski, A. M. Pilon, I. Iwamoto, K. Marubashi, S. Watanabe, H. Mori, and E. Sagawa, The suprathermal ion mass spectrometer (SMS) for the Akebono (EXOS-D) spacecraft, J. Geomagn. Geoelectr., 42, 511-536, 1990.

Whalen, B. A., S. Watanabe, and A. W. Yau, Thermal and suprathermal ion observations in the low altitude transverse ion energization region, Geophys. Res. Lett., 18, 725-728, 1991.

Yau, A. W., B. A. Whalen, A. G. McNamara, P. J. Kellogg, and W. Bernstein, Particle and wave observations of low-altitude ionospheric ion acceleration events, J. Geophys. Res., 88, 341-355, 1983.

Yau, A. W., E. G. Shelley, W. K. Peterson, and L. Lenchyshyn, Energetic auroral and polar ion outflow at DE 1 altitudes: Magnitude, composition, magnetic activity dependence, and long-term variations, J. Geophys. Res., 90, 8417-8432, 1985.

Yau, A. W., B. A. Whalen, C. Goodenough, E. Sagawa, and T. Mukai, EXOS-D (Akebono) observations of molecular $\mathrm{NO}^{+}$and $\mathrm{N}_{2}^{+}$upflowing ions in the high-altitude auroral ionosphere, J. Geophys. Res., 98, 1120511224, 1993. 